\title{
Annual Exhibition of the Physical and Optical Societies.
}

THE Imperial College of Science and Technology London, was once more the scene of the annual exhibition (the nineteenth) of the Physical and Optical Societies on Jan. 8, 9, and 10. The large number of visitors again testified to the widespread interest in the Exhibition on all sides, and its usefulness to trade and industry was evident by the exhibits, bewildering in their number and variety, of the various sections. The general arrangements were similar to those of last year, and congratulations must once more be offered to Mr. T. Martin as secretary, on the success which attended the Exhibition and to all those responsible in various ways for their unfailing courtesy and helpfulness.

It is impossible in a short description to do justice to every part of the Exhibition, and the only plan that can be followed, therefore, is to mention, so far as possible, some of the exhibits typical of recent developments in research and industry.

In the Trade Section there were eighty-two exhibiting firms. Among their exhibits the following may be mentioned : Messrs. Baird and Tatlock, Ltd., the Sutton photometer bench and a pump with double-acting pistons for aerating aquaria tanks, etc., its special attributes being its silent action and economy in use. Bakelite, Ltd., a new flaked fabric moulding material, particularly resistant to shock. The British Metallising Company, Ltd., had an exhibit illustrating the present and possible uses to scientific instrument manufacturers of their process of producing a metal film or coating firmly adherent to a non-metallic base, on which in turn a large range of non-ferrous metals may afterwards be plated to any desired thickness. The Cambridge Instrument Company, Ltd., the Campbell A.C. Potentiometer (Larsen type); a modified form of the photoelectric microphotometer originally developed by Dr. G. M. B. Dobson, a new portable form of electrocardiograph, and other novelties. The Edison Swan Electric Company, Ltd., various Ediswan battery eliminating devices for wireless receivers and other devices for wireless outfits, and a gas-filled rectifier for heavy currents for charging car batteries. The Foster Instrument Company, the intrascope, a new instrument for internal examination of tubes, bores, and other enclosures in which, by means of a novel optical system, examination of industrial structures can be made in the same way as with the cystoscope on the human body. The Research Laboratories of the Gramophone Company, Ltd., a logarithmic recording galvanometer, by means of which the electrical response curve characteristic of a gramophone pick-up can be obtained photographically and plotted automatically with a logarithmic scale; a demonstration of the vibrations of a membrane type loud speaker by means of lycopodium powder aroused much interest. Messrs. Hilger, Ltd., Dr. Jean Thibaud's grating spectrograph for the study of soft $X$-rays and of the extreme ultra-violet, in which the ruled grating is so placed that the incident rays fall almost tangentially upon its surface; some samples of pure earths--spectroscopically standardised substances. The Igranic Electric Company, Ltd., the transverse current microphone, the Phonovox electrical reproducing equipment. Messrs. E. Leitz, London, a new pattern ultra-microscope for the investigation of elements in colloids. Marconi's Wireless Telegraph Company, Ltd., a signal strength measuring set with a wave range of 14-5000 metres; a tuning-fork and thermostat unit for maintaining constant frequency in facsimile transmission. The M. L. Magneto Syndicate, Ltd., Coventry, the M-L noise comparator-an instrument designed to give a quantitative measure for noises in industrial mechanism, a direct-reading apparatus which requires no aural observation, and can be operated by an unskilled observer. The National Glass Industry, Dewar's flasks for liquid air, etc., and various experimental glassware. Negretti and Zambra, a new industrial type of ventilated hygrometer, a new recording rain gauge to overcome the difficulties of the self-syphoning type. Siemens Brothers and Co., Ltd., distance thermometers of various types, the substantial construction of these being of particular note. H. Tinsley and Company, a portable electric harmoniser under the patent of Prof. Miles Walker. Messrs. Beck, various new microscopes, including the No. 22 metallurgical microscope. Messrs. Carl Zeiss, London, Ltd., a hand sugar refractometer, and refractometer for the oil and sugar industries. Messrs. Bellingham and Stanley, Ltd., showed a new model critical angle refractometer, quartz spectrographs, etc.

In the Research and Experimental Section there were sixteen groups of exhibits illustrating recent physical research. The Brown Firth Research Laboratories had an interesting demonstration of dyed fabrics, showing in a striking manner the different tints of colour obtained when using container vessels of enamelled iron (taken as standard), copper, iron, nickel, lead, and Firth 'staybrite' steel. Among other examples of the applications of photoelectric cells, the Research Laboratories of the General Electric Company showed an apparatus for the detection of dust or smoke in air or gases. The National Physical Laboratory supplied eleven exhibits, among which may be mentioned Dr. D. W. Dye's interferometer for the examination of the modes of vibration of piezo-electric quartz plates ; by means of this apparatus the interference fringes are disturbed by the vibration of the quartz plates and the whole area can be mapped into its nodal and antinodal parts; and a beat tone oscillator as a low and telephonic frequency source of good wave form and constant output for testing purposes; a high temperature resistance furnace and electric radiator by Dr. W. Rosenhain and Mr. W. E. Prytherch, in which the heater elements are of particular note; a method of measuring flame temperature by spectrum reversal by Dr. Ezer Griffiths and Mr. J. H. Awbery. The Air Ministry Section of the Meteorological Office had five exhibits, including a sky-photometer and an electrical winddirection recorder. Prof. E. W. Scripture, of Vienna, showed a graphic apparatus for the registration of speech, and the strobilion, an apparatus for rendering the frequency of the voice tone visible. Dr. J. H. Vincent showed some experiments in magnetostrictive oscillations at audio and radio frequencies.

In the section devoted to lecture and instructional experiments in physics, Mr. S. R. Humby gave some beautiful demonstrations of experiments by means of a modified Tyndall apparatus, showing that the laws of reflection of light hold accurately for soundillustrating Lloyd's single mirror fringes, Lippmann's stationary light waves and other effects. Messrs. W. and T. Avery, Ltd., Research Department, had a number of exhibits illustrating the mechanics of the freely suspended beam and of linked weighing mechanisms. Other exhibitors in this section were Mr. J. E. Calthrop, Dr. R. S. Clay, Mr. C. W. Hansell, Dr. L. F. Richardson and others of Westminster Training College, Dr. G. D. West, and the Physics Department of the Wigan and District Mining and Technical College.

The Historical Section again provided an oppor-

No. 3090 , Vou. 123] 
tunity for a survey of past development in science, all the more striking for being placed near the exhibits of such modern developments as those of the Igranic and Gramophone and other companies. The exhibits included some examples of scientific instruments to illustrate the work of a series of London instrument makers in direct succession from Christopher Cock (seventeenth century) to Elliott (nineteenth century), contributed by Mr. 'T. H. Court, among which may be noted Robert Hooke's own microscope; photographs of the original apparatus used by Alessandro Volta in his researches of 1763-1819, exhibited by $\mathrm{Mr}$. Robert W. Paul ; and some early and primitive timemeasuring devices contributed by the Science Museum, from early Egyptian water clocks to a seventeenthcentury turret clock from St. Giles' Church, Cambridge.

The discourses once more attracted keenly interested audiences, whose appreciation was obvious. That on the first evening was delivered by Prof. F. Lloyd Hopwood, whose subject was "Experiments with High Frequency Sound Waves." He made use of a quartz piezo-electric oscillator, the crystals being cut in the form of circular dises with their plane faces parallel to the optical axis and at right angles to an electric or binary axis. This method of producing vibrations is due to Prof. Langevin, of Paris, and many practical applications of it have been made both in peace and war. The quartz discs were immersed in transformer oil contained in glass tanks, suitable arrangements being made for producing both horizontal and vertical beams of sound. The method used in connexion with a horizontal beam was due to Prof. R. W. Boyle, and exemplified stationary waves fobtained by reflection and rendered visible by the striæ formed in dust lying on a horizontal sheet of glass in the path of the beam), interference patterns, defraction effects ; attenuation (observed by bringing into action the frictional dissipation of energy due to the viscosity of the oil vibrating in a confined space, achieved quite simply by supporting a second glass plate almost in contact with the fir s; pressure of sound radiation, shown by means o Langevin's acoustic radiometer. Some biological effects brought about by the agency of ultra-sonic sound waves were then described and illustrated by means of slidesa beautiful example being the segregating of the chloroplasts in the fresh-water plant Nitella. By making use of a vertical beam of ultra-sonic waves some experiments were shown illustrating phenomena not usually associated with sound. These depend on the effect of pressure due to radiation on the surface of oil, which is strikingly shown by the formation of a mound of oil which erupts drops like a miniature volcano. By plunging vessels of appropriate form into this mound, vibrations of great intensity are communicated to the walls of the vessel, or through the walls to liquids contained in them. By these means it is possible to show cavitation in water; the vaporisation of benzene; transverse vibrations of a solid by the pattern -produced in a test tube dusted with lycopodium powder; and the calorific effect by melting a wax ball, which can be made to simulate the descent of a time ball.

On the second evening, Mr. Conrad Beck discoursed on "Lenses." The Greeks, he said, at least as early as 430 B.c., learnt that a piece of glass with curved surfaces could be used as a burning glass, and the derivation of the word 'focus' is from the word meaning 'altar' or place of fire. Text-books treat the focus as a geometric point formed by light entering the lens as a parallel beam. This is incorrect and leads to misconception. The focus of the ancients was a finite spot and not a point. Mr. Beck said that the way to understand the action of a lens is to study how it produces an image, for which three processes are necessary : the production of an image of a spot in the centre of the object on the axis ; the direction of the axial rays from spots on the object away from the axis ; and the examination of a complete bundle of rays from the marginal spot on the object. The Gallilean field glass, telescopes, periscopes, photographic and projecting lenses were discussed, and the study of the Gauss theory for the invention of new and original types of instruments was advocated. Mr. Beck considers that great attention should be paid to the more elementary principles of image formation before the questions of the correction of aberrations or the considerations of diffraction are investigated.

The lecture on the third evening, entitled "Some Colour Problems in Photo-Engraving," was given by Mr. A. J. Bull, and dealt with the effects in threecolour printing of errors in the selective absorption of the three-colour 'filters' and printing inks. Experiments were shown in which white light was imitated by superposing the colours transmitted by threecolour 'filters,' and it was shown that to obtain a white a larger area of blue filter is required than green, and a larger area of green filter than red-blue, green, red being the order of their increasing transparency. The colours obtainable are, however, fairly pure and close to theoretical requirements, so that screen plate processes give colour photographs which are fairly accurate as to colour but much lower in tone. This was shown by examples with the Lumière Autochrome plate. The ideal double colours which are desirable for the purposes of printing were shown by optical superposition of red and green images to obtain a yellow printing colour, green and blue images to obtain a 'blue' printing colour, and blue and red images to obtain a magenta or ' red' printing colour. These were contrasted with the colours of inks actually obtainable and the inaccuracies introduced were shown. These take the form of darkening blues and greens and a loss of reflected blue light with purples and pinks. The methods used for retouching were indicated; in half-tone work the skill of the colour etchers is such that excellent colour prints can be obtained by them from monochrome originals. KathleEN E. Bingham.

\section{Annual Conference of the Geographical Association.}

' HE annual conference of the Geographical Associa1 tion was held at the London School of Economics on Jan. 3-5. In addition to the usual business meetings, and some discussions on special problems of the teaching of geography, there were public lectures on some recent research work; and the chief part of the presidential address was also concerned with geographical investigation. The president, Sir H. G. Lyons, gave a concise review of the year's activities and then indicated the vast mass of material now available for geographical study in the reports and maps of the many national and other surveys now at work, and some of the difficulties of access to this material. He suggested that the Association should seek the co-operation of other interested societies in attempts to obtain some satisfactory classification of, and readier access to, this material.

Of the four main papers, ${ }^{1}$ three dealt with human

1 Geomorphological Problems of the Fastern Alps, by Prof. J. Sölch. Natural Environment related to Fuman Activity in the Corn Belt of North America, by Dr. P. W. Bryan. The Balance of Urban and Rural Populations, by Prof. C. B. Fawcett. On Linguistic Frontiers in the
Borderlands of German Speech, by Dr. Vaughan Cornish. 